Forthcoming in International Journal of Law and Psychiatry

\title{
Depression and suicide are natural kinds: Implications for physician-assisted suicide
}

\author{
Jonathan Y. Tsou \\ Department of Philosophy and Religious Studies, Iowa State University
}

\begin{abstract}
:
In this article, I argue that depression and suicide are natural kinds insofar as they are classes of abnormal behavior underwritten by sets of stable biological mechanisms. In particular, depression and suicide are neurobiological kinds characterized by disturbances in serotonin functioning that affect various brain areas (i.e., the amygdala, anterior cingulate, prefrontal cortex, and hippocampus). The significance of this argument is that the natural (biological) basis of depression and suicide allows for reliable projectable inferences (i.e., predictions) to be made about individual members of a kind. In the context of assisted suicide, inferences about the decision-making capacity of depressed individuals seeking physician-assisted suicide are of special interest. I examine evidence that depression can hamper the decision-making capacity of individuals seeking assisted suicide and discuss some implications.
\end{abstract}

Keywords: natural kinds, depression, suicide, monoamine hypothesis, assisted suicide 


\section{Introduction}

What kind of thing is classified by the term 'suicide'? Is it a medical condition? Or is suicide better understood as a social (or socially constructed) phenomenon? This article addresses these questions by focusing on the question of whether depression and suicide are natural kinds. I subsequently examine what bearing these issues regarding the naturalness of suicide have on the thorny issue of assisted suicide.

A high proportion of patients who request physician-assisted suicide are suffering from depression or present depressive symptoms (Levene \& Parker, 2011). This circumstance raises important questions about how depression affects individuals' judgments about ending their lives, and in particular, whether depression hampers individuals' capacity to make competent decisions about assisted suicide. Moreover, the high prevalence of depression among individuals seeking physician-assisted suicide highlights the importance of issues regarding the specific ways in which depression can alter patients' decision-making process and the extent to which the kinds of depression that are a precursor to suicide are treatable.

The article proceeds as follows. In sections 2 and 3, I examine questions concerning the naturalness of depression and suicide. In section 2, I critically examine the views of Thomas Szasz and Ian Hacking who offer different reasons for rejecting the existence of natural kinds in psychiatry. I subsequently propose a positive theoretical account of natural kinds in psychiatry that maintains that some mental disorders are natural kinds insofar as members of a kind share the same biological causal structure. More specifically, natural kinds in psychiatry (e.g., schizophrenia, bipolar disorder) are stable objects of classification whose characteristic signs are determined by networks of stable biological mechanisms. Analyses of Szasz and Hacking fail to establish that these natural kinds (i.e., mechanistic property cluster kinds) do not exist. In section 3 , I argue that depression and suicide are natural kinds because they are classes of abnormal behavior associated with serotonin dysfunction in various brain structures (i.e., the amygdala, anterior cingulate, prefrontal cortex, and hippocampus). In section 4 , I consider the implications of this analysis for assisted suicide. My focus is on questions concerning the extent that depression hampers individuals' capacity to make sound decisions and the potential to treat more severe forms of depression.

\section{Natural kinds in psychiatry}

In philosophy of science, the distinction between natural kinds and artificial kinds refers to a distinction between kinds (or classes) of things that are discovered and invented respectively (see Bird \& Tobin, 2010). Natural kinds are classes of naturally occurring objects, properties, or processes that exist independent of and are discovered by classifiers (e.g., electrons, gold, $\mathrm{H}_{2} 0$, fish). By contrast, artificial kinds are classes of objects that are imposed on nature and invented by classifiers (e.g., chairs, paperweights, toys, games). Hence, natural kinds are thought to be naturally occurring ('real') phenomena that are the proper objects of scientific study (e.g., fundamental particles in physics, elements in chemistry, and species in biology); artificial kinds, by contrast, are arbitrary or invented classes that serve some useful social function for classifiers, 
but do not have a natural basis. ${ }^{1}$ In examining natural kinds in psychiatry, I am especially interested in the kinds of objects that are individuated by human science classifications. While some human science classifications (e.g., 'introversion,' 'puberty,' 'breast cancer,' 'HIV') individuate classes of people in terms of a discoverable natural property or set of natural properties, other classifications (e.g., 'policemen,' 'liberals,' 'spouse,' 'widows') individuate groups of people in terms of purely conventional properties, i.e., properties that do not necessarily have a natural basis, but are convenient for distinguishing a social group.

\subsection{Skeptics of natural kinds in psychiatry}

Thomas Szasz $(1960,1974)$ has argued that the objects classified in psychiatry ('mental illnesses') do not refer to natural kinds that are discovered, but artificial kinds that are invented. He argues that 'mental illness' is a term that-in reality—refers to problems in living (i.e., the undesirable thoughts, feelings, and behaviors of individuals). Within this theoretical framework, Szasz draws a distinction between bodily illnesses (which are natural kinds) and mental illnesses (which are artificial kinds). As Szasz (1998) puts it:

Mental illness is a metaphor (metaphorical disease). The word "disease" denotes a demonstrable biological process that affects the bodies of living organisms (plants, animals, and humans). The term "mental illness" refers to the undesirable thoughts, feelings, and behaviors of persons. Classifying thoughts, feelings, and behaviors as diseases is a logical and semantic error. (Szasz 1998, emphasis added)

Szasz's analysis draws a strict distinction between bodily illnesses (which are objectively determined and matters of fact) and mental illnesses (which are subjectively determined and social inventions). According to this view, 'mental illness' refers to thoughts, feelings, and behaviors that are disapproved of by society (not thoughts, feelings, and behaviors that are caused by pathological biological processes). For Szasz (1960), this state-of-affairs marks a significant difference in the logic of bodily illness and mental illness:

The concept of illness, whether bodily or mental, implies deviation from some clearly defined norm. In the case of physical illness, the norm is the structural and functional integrity of the human body. ... [W] hat health is can be stated in anatomical and physiological terms. What is the norm deviation from which is regarded as mental illness? .. . [W] [Watever this norm might be, we can be certain . . . that it is a norm that must be stated in terms of psycho-social, ethical, and legal concepts. (p. 114, emphasis in original)

Szasz's rationale for rejecting natural kinds in psychiatry is premised on the idea that the relevant norms for determining mental illnesses - as opposed to bodily illnesses - are social rather than natural (i.e., biological).

In an analysis that also appeals to the social aspects of psychiatry, Ian Hacking (1999, ch.

4) has argued that the objects of classification in psychiatry are 'human kinds' (or 'interactive

\footnotetext{
${ }^{1}$ While some artificial kinds may have a natural basis, this basis is typically not the scientifically interesting (i.e., law-like) type of natural basis characteristic of natural kinds. Conversely, all natural kinds are artificial insofar as they are classes (e.g., species, race) individuated relative to various human interests. In section 2.2 of this article, I suggest that the distinction between natural and artificial kinds is best understood as a distinction in degree (cf. Dupré, 1981, 1993, 2001, 2002; LaPorte, 2004).
} 
kinds') that are fundamentally different from the natural kinds studied in the natural sciences. According to Hacking, most objects of classification in the human sciences-in contrast to objects of classification in the natural sciences-are inherently unstable objects of classification because of the 'looping effects of human kinds' (Hacking, 1986, 1995, 2007a). Looping effects are social feedback effects of human science classifications, wherein the meaning of a classification (e.g., 'depression,' 'homosexuality,' 'multiple personality') can affect and change the experiences and behavior of people who are so classified (e.g., an individual diagnosed with depression acts in accordance with the expectations and stereotypes associated with the depression label). Because the objects of classification in the social sciences - unlike those in the natural sciences - are aware of how they are classified and will change in response to how they are classified (in unpredictable ways), Hacking maintains that the objects of study in the human sciences are inherently unstable. As Hacking (1999) puts it: "The targets of the natural sciences are stationary. Because of looping effects, the targets of the social sciences are on the move" (p. 108, emphasis added). More recently, Hacking (2007a) has articulated this idea as follows: We think of . . kinds of people [e.g., obese people or impoverished people] . . a as definite classes defined by definite properties [i.e., natural kinds]. . . But it is not quite like that. They are moving targets because our investigations interact with the targets themselves, and change them. And since they are changed, they are not quite the same kind of people as before. The target has moved. That is the looping effect. (p. 293, emphasis added)

Here, Hacking makes the radical suggestion that-because of looping effects-the objects of human science classifications (i.e., kinds of people) are perpetually unstable entities. The idea is that because classifications in the human sciences causally affect the people being classified, the classified people will constantly be changing (and their associated classifications will need to be constantly revised in order to accommodate such changes). This is the sense in which Hacking maintains that the objects of classification in the human sciences are not natural kinds.

The arguments presented by Szasz and Hacking do not preclude the existence of natural kinds in psychiatry. With respect to Szasz, it is clear that his analysis does not present a fair formulation of what mental illness is. Recall Szasz's claims that:

(1) 'bodily illness' refers to a demonstrable biological process that affects the bodies of living organisms.

(2) 'mental illness' refers to the undesirable thoughts, feelings, and behaviors of persons.

Szasz's analysis clearly equivocates on what 'illness' means. In the formulation above, 'mental illness' refers to the symptoms (or characteristic signs) of mental illness in (2), whereas 'bodily illness' refers to the cause of symptoms in (1). On a more consistent and charitable rendering, Szasz would be obligated to claim that:

(1) 'bodily illness' refers to a demonstrable biological process that affects the bodies of living organisms.

$\left(2^{*}\right)$ 'mental illness' refers to a demonstrable biological process that affects the thoughts, feelings, and behaviors of persons.

I submit that some mental disorders are natural kinds as formulated in $(2 *)$ insofar as there is good evidence that the symptoms of some disorders (e.g., schizophrenia, bipolar disorder, 
depression) are caused by demonstrable biological processes. ${ }^{2}$ Moreover, as others have pointed out (e.g., see Boorse, 1976; Kendall, 1975; Sedgwick, 1982), Szasz's argument ultimately hinges on an untenable distinction between bodily illness and mental illness. Szasz presupposes an unrealistic view, in which physical illnesses are determined in an objective and value-free manner (while mental illnesses are not). It is clear, however, that all attributions of illness (both physical and mental) require the normative value-judgment that a condition is harmful or undesirable (e.g., because it compromises an individual's ability to survive or lead an otherwise normal life). ${ }^{3}$ If one assumes a more nuanced view of bodily illness (which also require value judgments), then there is no principled difference in the determination of bodily and mental illness. The determination of any illness requires both the presence of a demonstrable biological process (which is natural) and the value-judgment that the effects of that process are harmful (which is social). ${ }^{4}$ What makes an illness a natural kind is the presence of a demonstrable biological process.

With respect to Hacking's analysis, the putative existence of looping effects does not necessarily compromise the stability of objects of psychiatric classification (Tsou, 2007). Looping effects are a ubiquitous feature of most human science classifications. For looping effects to render an object of classification unstable in the way suggested by Hacking, however, something very specific needs to occur. Looping effects must change the experiences and behavior of individuals who fall under a classification in a uniform manner. Moreover, a sufficient number of individuals need to be uniformly changed by looping effects such that the criteria that constitute membership for that classification must be revised. Although these drastic kinds of consequences of looping effects do sometimes occur, more often than not, the consequences of looping effects are much more innocuous. On this view, mental disorders that are natural kinds remain stable in spite of looping effects. This follows from the fact that members of a kind share a similar biological causal structure, which ensures that the characteristic signs of such disorders remain stable over time.

\footnotetext{
${ }^{2}$ In this article, the relevant demonstrable biological processes in both physical and mental illness are conceptualized to be dysfunctional biological processes that deviate from species-typical normal functioning (see Boorse, 1975, 1976, 1977, 1997; Daniels, 1981, 1985, 2008).

${ }^{3}$ Peter Sedgwick (1982) expresses this complaint aptly as follows:

[T] here is no reason to believe that the 'standardized' varieties of human pathology [i.e., physical illnesses] operate to a different logic from 'culturally' dependent varieties [e.g., mental illnesses]. The existence of common or even universal illnesses testifies, not to the absence of a normative framework for judging pathology, but to the presence of very wide-spread norms . . The attribution of illness always proceeds from the computation of a gap between presented behavior (or feeling) and some social norm. (pp. 33-34, emphasis added)

${ }^{4}$ The reason why there appears to be a fundamental difference between bodily and mental illnesses is because there is greater disagreement over whether the effects of mental illnesses are harmful. While most bodily illnesses (e.g., cancer, tuberculosis) are clearly harmful because they compromise an individual's ability to survive or lead a normal life, the harmful effects of some mental disorders listed in the DSM (e.g., ADHD, male erectile disorder) are much more controversial. For these more controversial disorders, the ideal that is implicitly being contrasted with harm is optimality, rather than normality. As a more conservative criterion (see Boorse, 1977), one could stipulate that genuine illnesses are interferences with normal biological functioning that are harmful insofar as they compromise an individual's capacity to lead a normal unimpeded life. On this view, the ideal that is contrasted with illness is not optimal health, but normal health.
} 


\subsection{Some mental disorders are mechanistic property cluster kinds}

Among the various mental disorders listed in the DSM (APA, 2000), some disorders are more natural than others. ${ }^{5}$ From this perspective, natural kinds in psychiatry are objects of classification that are associated with a predictable (natural) biological basis, as opposed to objects of classification that do not. In the following section, I articulate a theoretical account of natural kinds in psychiatry, which draws upon Richard Boyd's account of homeostatic property cluster (HPC) kinds.

In offering a theoretical account of mental disorders as natural kinds, I assume that the distinction between natural kinds and artificial kinds is best understood as a distinction of degree, not a distinction of kind (see LaPorte, 2004, pp. 20-27). Psychiatric classifications-like all scientific classifications - are inevitably theory-laden (and thus conventional) since they are formulated relative to certain human values, interests, and standpoints. However, this theoryladeness does not vitiate the fact that some classifications will pick out classes that are more natural than others (cf. Slater, 2005). ${ }^{6}$ I examine classes of abnormal behavior that fall on the 'more natural' end of the natural-artificial spectrum insofar as these classes can-to a large extent - be individuated in terms of a set of natural properties.

The biological mechanisms that underwrite a cluster of abnormal behaviors and psychological processes establish some mental disorders as natural kinds because members of these kinds share a similar biological causal structure. This perspective draws on Richard Boyd's $(1991,1999)$ homeostatic property cluster (HPC) theory of natural kinds, which defines HPC kinds in terms of the following characteristics (see Boyd, 1988, p. 197; 1989, pp. 16-17; 1990, pp. 373-374; 1999, pp. 143-144):

(1) There is a family $(F)$ of properties that are contingently clustered in nature.

(2) Their co-occurrence is the result of what may be (metaphorically or literally) described as homeostasis; either the presence of some properties tends to favor the presence of others, or there are underlying mechanisms that tend to maintain the properties in $F$, or both.

(3) There is a kind term $(t)$ that is applied to things in which the homeostatic clustering of most of the properties in $F$ occurs.

\footnotetext{
${ }^{5}$ Zachar (2000) argues that no psychiatric disorders are natural kinds and that all psychiatric disorders are 'practical kinds.' This stance is unreasonable insofar as it assumes (like Szasz) that all the disorders listed in DSM fall under a single monolithic category (cf. Haslam, 2002). Zachar's idea of 'practical kinds' (viz., stable patterns that can be identified with varying levels of reliability and validity) is also too vaguely formulated to be useful.

${ }^{6}$ In response to the murkiness of the natural kind concept, Hacking (2007b) argues that: "Some classifications are more natural than others, but there is no such thing as a natural kind" (p. 203, emphasis in original). This defeatist attitude, however, is not the only response one can make. As Hacking acknowledges, another way of facing this murkiness is to adopt what John Dupré $(1993,2001,2002)$ calls 'promiscuous' or 'pluralistic' realism. Dupré (1981) describes this position as follows: "The realism derives from the fact that there are many sameness relations that serve to distinguish classes ... in ways that are relevant to various concerns; the promiscuity derives from the fact that none of these relations is privileged" (p. 82, emphasis added). On this view, there are many classifications that — given different human interests - yield classes that merit the label of natural kinds. The stance on natural kinds adopted in this article follows Dupré's pluralistic approach; in Hacking's terminology, I am interested in psychiatric disorders that fall on the 'more natural' end of the classification spectrum.
} 
Boyd's HPC theory offers a useful account of how members of psychiatric kinds share the same biological causal structure (see Beebee \& Sabbarton-Leary, 2010; Cooper, 2005, ch. 2, 2007, ch. 4; Murphy, 2006, ch. 9). Within this framework, the characteristic signs of a mental disorder can be understood as the cluster of properties $(F)$, while its biological causes are the mechanisms referred to in (2) that tend to maintain these properties.

Applying Boyd's HPC theory, Kendler, Zachar, and Craver (2011) argue that natural kinds in psychiatry are best understood as mechanistic property cluster (MPC) kinds: kinds that are constituted by networks of biological mechanisms at multiple levels (e.g., molecular, developmental, neurobiological) that interact to produce the key features of the kind. ${ }^{7}$ An important feature of the MPC view of natural kinds is that it can explain the 'projectability' of natural kind terms $(t)$-i.e., it can account for how successful inferences about members of a kind can be made on the basis of induction - which is a fundamental aim of any satisfactory account of natural kinds (see Boyd, 1985, 2010; Goodman, 1983; Quine, 1969). It is the shared causal structure captured by a natural kind term $(t)$ that allows for successful inductive inferences about members of a kind. In the case of mental disorders that are MPC kinds, this importantly includes inferences regarding the prognosis of a particular disorder and predictions concerning how an individual diagnosed with a disorder will respond to specific treatment interventions. Moreover, the shared causal structure of mental disorders that are MPC kinds can also account for the relative stability of such kinds over time. Because the characteristic signs of MPC kinds are constituted by stable ('homeostatic') networks of biological mechanisms, MPC kinds are stable objects of classification.

Some mental disorders are suitable examples of MPC kinds because there are good reasons for thinking that their characteristic signs are underwritten by a set of stable biological mechanisms. For instance, some forms of mental retardation (e.g., Down syndrome) are known to be caused by a specific chromosomal abnormality (e.g., trisomy on chromosome 21), which causes predictable biological changes that impair the normal development of the brain (Gardner $\&$ Sutherland, 2004, ch. 16). There are also good reasons for regarding other mental disorders as MPC kinds constituted primarily by neurobiological mechanisms. For example, the psychotic ('positive') symptoms of schizophrenia (i.e., delusions, hallucinations, and thought disorder) are known to be caused by specific neurobiological mechanisms, such as excessive dopamine activity in the mesolimbic pathway (Tsou, 2012). In these examples, there is a distinctive biological causal structure associated with MPC kinds. By contrast, other mental disorders (e.g., hysteria, drapetomania, mathematics disorder, narcissistic personality disorder) are artificial kinds because the characteristic signs associated with these classifications are constituted primarily through social mechanisms (e.g., labeling, role adoption) and these disorders lack a distinctive biological causal structure (see note 1 above).

\footnotetext{
${ }^{7}$ In this article, I assume that mechanisms are complex systems of entities and activities that are organized in a way to produce regular changes (see Bechtel \& Richardson, 1993; Craver \& Darden, 2001; Glennan, 1996, 2002; Machamer, 2004; Machamer, Darden, \& Craver, 2000; Tabery, 2004).
} 


\section{Are depression and suicide natural kinds?}

In the following section, I argue that depression and suicide are natural kinds insofar as they are classes of (abnormal) behavior that are underwritten by stable neurobiological mechanisms. In articulating this argument, I presuppose a diathesis-stress model wherein individuals may inherit a neurobiological vulnerability to depression and suicide (Mann et al., 1999). In this model, individuals who inherit a susceptibility (diathesis) to depression and suicide are more likely to exhibit depressed symptoms or suicidal behavior in response to stress. Hence, my argument can be understood as the claim that there is an inherited vulnerability to depression and suicide that is identifiable at the neurobiological level. While research indicates that the expression of depression and suicide is mediated by social factors, this does not vitiate the fact that they are natural (i.e., mechanistic cluster property) kinds.

In discussing depression and suicide as natural kinds, it should be stated at the outset that depression and suicide are different kinds of kinds. Depression is a mental disorder, while suicide is a behavior that is caused by depression. Accordingly, the kind of suicide examined in this article is limited to suicidal behavior (or suicide ideation) that results from major depression. The analysis of this article is not intended to apply to other kinds of suicide, such as suicide that is committed out of a sense of duty (see Cholbi, 2011, 2012).

\subsection{The biological basis of depression}

Depression (major depressive disorder) is classified in DSM-IV-TR as a mood disorder, and it is characterized by profound feelings of sadness and an inability to experience pleasure (APA, 2000, pp. 369-382). Other characteristic signs of depression include fatigue, low energy, physical aches, sleep disturbances, loss of appetite, low sex drive, and lack of initiative. To receive a diagnosis of major depressive disorder in DSM-IV-TR, the following criteria must be present for at least two weeks (APA, 2000, pp. 356, 375-376):

A. Depressed mood (e.g., feelings of sadness or emptiness) or loss of pleasure in usual activities

B. At least four of the following symptoms must be present nearly every day:

(1) significant weight changes or changes in appetite

(2) insomnia or hypersomnia

(3) psychomotor agitation or retardation

(4) fatigue or loss of energy

(5) feelings of worthlessness or inappropriate guilt

(6) diminished concentration or indecisiveness

(7) recurrent thoughts of suicide, suicide ideation, or a suicide attempt

C. There is impairment in social or occupational functioning

Individuals who are clinically depressed are at serious risk for suicide. It has been estimated that $15.9 \%$ of people with unipolar depression and $29.2 \%$ of people with bipolar disorder attempt to commit suicide (Chen \& Dilsaver, 1996). 
Evidence that depression is a natural kind comes from multiple lines of research. Depression is observed in all cultures, although there is variability in the ways in which it is expressed across cultures (Kleinman, 1977, 1988, ch. 3; Kleinman \& Good, 1985). Major depression afflicts women two to three times more than men (Carlson, 2008, p. 471), and it is three times as common among low socioeconomic status groups (Kessler et al., 2003). Compared to disorders such as schizophrenia and bipolar disorder-which are associated with lifetime prevalence rates around 1\% - prevalence rates of depression are significantly higher and show greater variability across cultures (Ingram, Scott, \& Hamill, 2009, pp. 232-233; Weissman et al., 2010). Lifetime prevalence rates of depression have been estimated to be $4.9 \%$ by the Epidemiological Catchment Area study (Freedman, 1984) and 17.1\% by the National Comorbidity Survey (Kessler et al., 1994), making depression one of the most common mental disorders. In a cross-cultural study of depression conducted by the World Health Organization, a number of common symptoms were found among three quarters of depressed patients from countries across the world: sadness, joylessness, anxiety, tension, lack of energy, decreased interest and concentration, feelings of inadequacy, and feelings of worthlessness (Sartorius et al., 1983, p. 92). This finding is important as it suggests that there is a 'core' cluster of symptoms associated with depression.

Genetic research supports the view that depression is partly heritable. Twin studies have yielded heritability estimates of $37 \%$ for major depressive disorder (Kendler \& Prescott, 1999; Sullivan, Neale, \& Kendler, 2000), and these estimates are higher when samples are taken from more severe inpatient populations (Kring et al. 2007, pp. 237-238). Studies on specific genetic regions have identified polymorphisms in the serotonin transporter gene (5-HTTLPR), which is theorized to interact with environmental factors to increase the risk of depression (Ogilvie et al., 1996; Risch et al., 2009).

The most convincing evidence that depression is a natural kind comes from research on the neurobiology of depression. According to the 'monoamine hypothesis' (Carlson, 2008, pp. 476-477; Delgado 2000; Hirschfeld 2000; McKim, 2007, pp. 303-306; Owens 2004), depression is caused by deficient activity of monoamine neurotransmitters: norepinephrine (NE), serotonin (5-HT), and dopamine (DA). Evidence for the monoamine hypothesis comes from research on pharmacological interventions with depressed patients. ${ }^{8}$ Antidepressant drugs (e.g., MAO inhibitors, tricyclic antidepressants, specific serotonin reuptake inhibitors) that can relieve the signs of depression are all monoamine agonists that increase the activity of monoamine neurotransmitters. This hypothesis also receives support from the finding that monoamine antagonist drugs with opposite pharmacological effects as antidepressants (e.g., reserpine) can induce depressive symptoms in non-depressed individuals (Sachar \& Baron, 1979). Research has indicated that antidepressants exert their influence primarily on serotonin and norepinephrine

\footnotetext{
${ }^{8}$ I have elsewhere discussed the role of pharmacological drugs as experimental instruments that can help researchers identify the neurobiological causes of mental disorders (Tsou, 2012). In the context of neurobiological research, pharmacological drugs function as tools that enable researchers to access and detect the existence of stable neurobiological kinds. In this article, I assume that antidepressant drugs and other pharmacological drugs are experimental instruments that have aided in the identification of depression as a stable neurobiological kind. For a more comprehensive historical discussion of the discovery and evolution of antidepressant drugs - and their role in facilitating the formulation of neurobiological theories of depression - see Fangmann et al. (2008), Healy (1997), López-Muñoz \& Alamo (2009), and López-Muñoz et al. (2007).
} 
systems (since dopamine agonists such as amphetamines do not have an antidepressant effect), with serotonin specifically implicated (Maes \& Meltzer, 1995; Meltzer \& Lowy, 1987).

The monoamine hypothesis is limited insofar as absolute levels of neurotransmitters cannot tell the complete story about depression. Some important experimental findings in this connection are: (1) treating depression with pharmacological drugs takes one or two weeks, however, by this time, neurotransmitter levels have returned to their initial levels, and (2) metabolic studies have shown that some individuals with depression do not show evidence of abnormal absolute neurotransmitter levels (Kring et al. 2007, p. 239). In response to these findings, researchers have investigated the sensitivity of 5-HT receptors, and this research suggests that the diminished serotonin activity associated with depression is the result of insensitive 5-HT receptors. This view is supported by experiments utilizing trypotophan depletion methods (Delgado et al., 1990), in which researchers lower serotonin levels by depleting levels of tryptophan (which is the major precursor to serotonin) with a drink containing high levels of 15 amino acids and no tryptophan. Studies have demonstrated that depleting tryptophan (thereby lowering serotonin levels) causes temporary depressive symptoms among individuals with a history of depression, but not for individuals with no history of depression (Benkelfat et al., 1994; Johnson et al., 2009, pp. 203-204; Moore at al., 2000). This research suggests that individuals who have a vulnerability to depression have insensitive serotonin receptors.

Brain-imaging studies suggest that the main brain structures involved in depression are the amygdala, anterior cingulate, prefrontal cortex, and hippocampus (Kring et al., 2007, pp. 240-242). Functional activation studies indicate that major depression is associated with elevated activity in the amygdala and diminished activity in the anterior cingulate, prefrontal cortex, and hippocampus (Johnson et al., 2009, pp. 211-215). One theory, which is of particular relevance for the analysis of this article, suggests that depressed patients show greater emotional reactivity due to overactivity in the amygdala, but decreased ability to plan due to diminished activity in the anterior cingulate, prefrontal cortex, and hippocampus (Davidson et al., 2002). This follows from the premise that the amygdala is involved in assigning emotional significance to stimuli, while the prefrontal cortex, anterior cingulate, and hippocampus are structures involved in weighing rewards and costs, making decisions, and pursuing goals (Kring et al., 2007, p. 240241). One study using PET scans found that individuals with depression or a history of depression (compared to individuals without current or previous depression) showed less activity in the orbitofrontal cortex (in the prefrontal cortex) after being induced into a sad state (Liotti et al., 2002). This indicates that as people with current depression become sad, they present less activity in brain areas implicated in planning and executing plans.

Neuroendocrinological studies on depressed individuals have also revealed abnormalities in the hypothalamic-pituitary-adrenal (HPA) axis, which is the biological system that manages stress (Johnson et al., 2009, pp. 206-211; Kring et al., 2007, pp. 242-244). This research indicates that depression is associated with hyperactivity of the HPA axis and elevated levels of cortisol, which is a hormone that is released in response to stress (Nestler et al., 2002). Chronic activation of the HPA axis - which results in high levels of cortisol - can disrupt functioning in brain regions responsible for regulating mood (e.g., the hippocampus, prefrontal cortex, amygdala) as well as serotonin systems (Johnson et al., 2009, pp. 207-211). Thus, it is likely that depression involves a complex interaction between mechanisms involved in neuroendocrine responses (i.e., 
the HPA axis) and neurobiological mechanisms (e.g., serotonin systems), which can affect other brain regions (Nestler et al., 2002).

\subsection{The biological basis of suicide}

The question of whether suicide is a natural kind is an issue concerning whether suicide is best understood as a medical or social phenomenon. Within the theoretical framework of this article, this issue can be reduced to the question of whether there are stable and predictable biological mechanisms associated with suicide and suicide ideation. In what follows, I argue that suicide is a natural kind insofar as it is a class of abnormal behavior underwritten by a stable set of neurobiological mechanisms. In articulating this argument, I assume that depression is the major cause of suicide ideation and that there are mechanisms common to both depression and suicide; however, some evidence suggests that suicide has a biological basis that may — in partbe distinct from depression.

As many as $90 \%$ of individuals who commit suicide are suffering from some mental disorder (Mann, 1998, p. 25). Researchers have estimated that more than half the individuals who commit suicide are depressed (Henriksson et al., 1993), and suicides are most likely when an individual is experiencing depression (Angst et al., 2002; Linehan, 1997). Whereas the prevalence of depression is greater for women than for men, men are four times more likely than women to commit suicide (Arias et al., 2003). Psychological research has indicated that two of the best predictors for suicide attempts are problem-solving deficits (Dieserud et al., 2003; Keilp et al., 2001; Linehan \& Shearin, 1988) and hopelessness (Beck, Kovacs, \& Weissman, 1975; Brown et al., 2000; Weishaar \& Beck, 1992).

Multiple lines of research indicate that suicide is associated with a distinctive biological causal structure. Genetic studies suggest that suicide risk is partly heritable. Adoption and family studies have indicated that there is a genetic contribution to suicidal behavior that is independent of the heritability of other major psychiatric disorders (Brent et al., 1996; Egeland \& Sussex, 1985; Roy, 1986; Roy et al., 1991; Schulsinger et al., 1979). Twin studies have found that monozygotic (MZ) twins have a significantly higher concordance for suicide than dizygotic (DZ) twins (Roy, 1993; Roy, Segal, \& Sarchiapone, 1995; Statham et al., 1998).

The most convincing evidence that suicide is linked with distinctive biological mechanisms comes from research on the neurobiology of suicide. Just as deficient serotonin activity is implicated in depression, suicide appears to be related to low activity of serotonin. One line of research supporting this inference draws on the fact that lower production and release of serotonin in the brain is correlated with decreased Cerebrospinal Fluid (CSF) levels of 5HIAA (5-hydroxindoleacetic acid). Studies have found that CSF levels of 5-HIAA are significantly lower among individuals who have attempted suicide compared to controls and that lower levels of 5-HIAA are correlated with higher number of suicide attempts (Åsberg, Träskmann, \& Thorén, 1976; Roy, De Jong, \& Linnoila, 1989; Träskmann et al., 1981). Low CSF levels of 5-HIAA have also been reported in suicides with patients with schizophrenia and personality disorders, which suggests that the association between 5-HIAA and suicide may be independent of depression (Mann et al., 2001). Post-mortem studies have found increased numbers of postsynaptic serotonin receptors (e.g., 5- $\mathrm{HT}_{1 \mathrm{~A}}$ and $5-\mathrm{HT}_{2 \mathrm{~A}}$ receptors) in the prefrontal cortex of suicide victims, possibly due to a compensatory response to reduced 
serotonin activity (Mann, 1998, p. 26). While depression is associated with hyperactivity of the HPA axis, evidence suggests that suicide victims exhibit even greater hyperactivity (Bunney et al., 1969; Nemeroff et al., 1988).

\subsection{How do social factors affect depression and suicide?}

As discussed in section 2.1 of this article, theorists such as Szasz and Hacking appeal to social factors in their arguments against the existence of natural kinds in psychiatry. Evidence suggests that social factors play a strong role in the expression of depression and suicide; however, these social factors do not vitiate the fact that depression and suicide are natural kinds constituted by stable biological mechanisms.

The research reviewed above indicates that depression and suicide are natural kinds associated with a common neurobiological causal structure. The fact that there is a 'common core' of symptoms associated with depression (i.e., sadness, joylessness, anxiety, tension, lack of energy, decreased interest and concentration, feelings of inadequacy, and feelings of worthlessness) that is observed across cultures indicates that depression is a naturally occurring phenomenon, rather than a purely social phenomenon. Moreover, experimental interventions with depressed patients using pharmacological drugs provide clues about the neurobiological causes of depression. The evidence reviewed supports the inference that there are distinctive and stable neurobiological mechanisms that underwrite the characteristic signs of depression and suicide (e.g., diminished serotonin activity due to insensitive 5-HT receptors).

A consideration of cross-cultural research on psychopathology clarifies the sense in which some mental disorder are 'more natural' than others. This research indicates that both schizophrenia and depression are ubiquitous in all cultures; however, there is greater variability in the ways in which depression is expressed across cultures compared to schizophrenia, e.g., in non-Western cultures depressive signs are expressed more in terms of somatic complaints (Kleinman, 1977, 1988, ch. 3; Kleinman \& Good, 1985). One way to interpret these findings is to regard the uniformity of the expression of a disorder across cultures as a measure of the extent that a disorder is biologically determined (Tsou, 2007). This implies that some mental disorders that are constituted by stable biological mechanisms (e.g., Down syndrome, schizophrenia, bipolar disorder) are 'more natural' than other disorders because their stereotypical cluster of signs are more directly the result of biological mechanisms. This stance captures the intuition that the most natural kinds of mental disorders are biologically determined disorders, whose characteristic signs (or cluster of co-occurring properties) are directly determined by biological causes. By contrast, less biologically determined disorders lie at the 'more artificial' end of the classification spectrum because the expression of these disorders is more strongly mediated by social and cultural factors (and hence, looping effects); for this reason, one would expect to see greater variability in the cluster of co-occurring properties associated with such disorders. At the same time, it is important to reiterate that it is precisely the shared biological basis of these disorders that renders them mechanistic property cluster kinds. Conversely, purely socially constituted disorders (e.g., hysteria, narcissistic personality disorder, mathematics disorder) without a distinctive biological structure are not natural kinds and can be regarded as artificial classes of abnormal behavior. 
In this article, I assume that depression and suicide are influenced by social factors insofar as the expression of these conditions will be mediated by social and cultural factors. It is important to note, however, that this social mediation does not negate the fact that depression and suicide are natural kinds constituted by stable biological mechanisms. While the expression of a disorder may, due to social factors, vary both within and across cultures, I assume that there is a core cluster of properties (viz., the characteristic signs that are constituted by biological mechanisms) that will be common across different cultures and remain stable over time. This framework provides reasons to resist the conclusions reached by Szasz and Hacking. With respect to Szasz's argument, the fact that mental disorders (and medical disorders more generally) require evaluations that make reference to social norms does not preclude the possibility that mental disorders are underwritten by stable biological mechanisms. With respect to Hacking's argument, the fact that psychiatric classifications have feedback effects on the kinds of people being classified does not invalidate the possibility that the objects being classified refer to stable MPC kinds. ${ }^{9}$ Mental disorders that are natural kinds will remain stable in spite of looping effects because these disorders are constituted by a stable set of biological mechanisms.

\section{Implications for physician-assisted suicide}

Issues regarding the naturalness of depression and suicide are highly relevant for assisted suicide. In the context of physician-assisted suicide, the fact that depression is a natural kind is significant because it is precisely the natural (i.e., biological) basis of depression that allows physicians to make projectable inferences about patients who are considering assisted suicide. As discussed in the second section of this article, natural kind terms (e.g., 'depression,' 'schizophrenia') are projectable insofar as judgments about a member of a kind can be reliably extended to other members on the basis of induction. For mechanistic property cluster kinds such as depression, the projectability of natural kind terms is explained by the fact that there is a predictable biological causal structure shared by members of a kind. From this perspective, physicians can make reliable inductive inferences and predictions about disorders that are mechanistic property cluster kinds because members of these kinds are all constituted by a set of similar biological mechanisms.

Research indicates that a significant number of individuals seeking physician-assisted suicide or euthanasia are clinically depressed (Back et al., 1996; Ganzini, Goy, \& Dobscha, 2008; Lavery et al., 2001; van der Lee et al., 2005) and that desire for hastened death is significantly associated with a diagnosis of major depression (Breitbart et al., 2000; Breitbart, Rosenfeld, \& Passik, 1996; Chochinov et al., 1995; Kelly et al., 2003; Rosenfeld, 2000). In a meta-analysis of existing studies on the prevalence of depression in cases of assisted suicide, the authors concluded that around $25-50 \%$ of patients who have made requests for assisted suicide showed signs of depression and $2-10 \%$ of patients who have received physician-assisted suicide

\footnotetext{
${ }^{9}$ Hacking argues that suicide is not a natural kind and that the modern (medical) concept of suicide is a product of interactions between the statistical and medical sciences that began in the early nineteenth century (see Hacking, 1986; 1990, ch. 8; 1995; 2007a). Contra-Hacking, I want to suggest that suicide is a stable neurobiological kind and that various attempts to study it (and different meanings that have been attached to it) have not fundamentally changed the neurobiological nature of suicide.
} 
were depressed (Levene \& Parker, 2011). In a review of empirical studies on assisted suicide, Rosenfeld (2000) concluded that depression and other psychosocial factors (e.g., lack of social support) are significant contributing factors in determining an individual's desire for hastened death, and they appear to have a stronger causal influence than physical symptoms (e.g., pain).

\subsection{Does depression compromise decision-making?}

A crucial, yet poorly understood, question that is relevant for assisted suicide is whether depression compromises or otherwise hampers an individual's capacity to make competent decisions regarding ending his or her life. In what follows, I examine empirical evidence that the biological mechanisms implicated in depression (i.e., disturbances in serotonin systems) can hinder an individual's capacity to make competent decisions. Some studies have indicated that the decision-making capacity of depressed patients who have a history of suicide attempts is impaired compared to depressed patients who have not attempted suicide. This finding suggests that there may be high risk for decision-making deficits among depressed individuals who have a desire for hastened death or who are seeking physician-assisted suicide. I review some of these studies, focusing on the specific ways in which decision-making is compromised among individuals with depression.

Individuals with depression suffer cognitive impairments, especially on tasks of executive functioning, i.e., tasks related to problem solving, planning, and the initiation of behaviors (Austin et al., 1992; Degl'Innocenti, Ågren, \& Backman 1998; Fossati, Ergis, \& Allilaire, 2002; Goodwin, 1997; Martin, Oren, \& Boone, 1991; Powell \& Miklowitz, 1994; Veiel, 1997). For the purposes of this article, this finding is important since decision-making - such as the decision to end one's life - is a task of executive functioning. Given that individuals with depression show cognitive deficits in executive functions, there is prima facie reason to think that they are less likely to make competent decisions regarding ending their lives. Tasks of executive functioning are primarily carried out in the prefrontal areas of the frontal lobe, and brain imaging and postmortem studies with patients with major depression have found alterations in multiple areas of the prefrontal cortex, especially in the left dorsolateral prefrontal region (Kring et al., 2007, pp. 240-241; Marzuk et al., 2005, p. 295). Thus, empirical research supports the idea that the decision-making capacity among individuals with depression is compromised.

Cognitive rigidity has been theorized to be a specific impairment of executive functioning among suicidal individuals that may influence decisions concerning suicide (Keilp et al., 2001; Marzuk et al., 2005). Cognitive rigidity is a tendency towards dichotomous (all or nothing) thinking and cognitive inflexibility that makes it difficult for individuals to formulate alternative solutions to problems (Patsiokas, Clum \& Luscomb, 1979). Individuals who are cognitively rigid have a tendency to conceptualize their problems in dichotomous terms such as 'good or bad,' 'right or wrong,' etc. (Marzuk et al., 2005). This impairment is also characterized by an inability to identify problems and associated solutions (Schotte \& Clum, 1987). A number of studies have found that depressed individuals who have contemplated or attempted suicide are cognitively rigid (see Luscomb, Clum, \& Patsiokas, 1980; Neuringer, 1961, 1964; Patsiokas, Clum, \& Luscomb, 1979; Pollock \& Williams, 1998; Schotte \& Clum, 1987). One study found that, compared to depressed non-suicidal patients, depressed patients who had current suicide ideation performed significantly worse on several measures of executive functioning, including measures of executive functioning involving mental flexibility (Marzuk et al., 2005). Theoretical models 
of suicide that have attempted to relate problem-solving deficits to hopelessness have indicated that cognitive rigidity may be a cognitive trait that is concomitant to - rather than a cause ofdepression, hopelessness, and suicide ideation (Weishaar, 1996, pp. 240-242). Moreover, there is evidence that cognitive rigidity is a transient characteristic (rather than an enduring trait) of suicide attempters (Perrah \& Wichman, 1987). Regardless of how the relationship among depression, cognitive rigidity, hopelessness, and suicide ideation is theorized (e.g., see McLeavey et al., 1987; Rickelman \& Houfek, 1995; Schotte \& Clum, 1987; Weishaar \& Beck, 1992), research suggests that cognitive rigidity is a specific cognitive impairment among depressed patients who are contemplating suicide.

The decision-making impairment (i.e., cognitive rigidity) associated with suicidal patients is related to biological mechanisms that are known to be implicated in both depression and suicide. As discussed above, patients with depression present cognitive deficits in executive functions, which are known to be associated with dysfunction in the prefrontal cortex. An area of the prefrontal cortex of particular relevance is the orbitofrontal cortex. Lesion and functional imaging studies indicate that the orbitofrontal cortex is crucial for decision-making and that damage in this region leads to high-risk and disadvantageous decisions in real life (Damasio et al., 1994; Eslinger \& Damasio, 1985). A specific serotonin dysfunction that has been implicated in depressed patients with a history of suicide is serotonin projections to the orbitofrontal cortex and the brainstem (Mann, 1998). Hence, multiple lines of research suggest that cognitive rigidity can be usefully conceptualized - at the neurobiological level—in terms of a deficit of serotonergic projections to the orbitofrontal cortex, which contribute significantly to suicidal ideation (Jollant et al., 2005).

\subsection{Depression, decision-making, and assisted suicide}

Given that there are predictable impairments in decision-making among some depressed patients with a desire for hastened death, what bearing does this fact have for the issue of assisted suicide? In addressing this question, several qualifications should be made at the outset. First, studies on cognitive rigidity involve samples of clinically depressed patients who may differ in important respects from the groups of patients seeking physician-assisted suicide. Second, it is unclear precisely how the cognitive deficits in decision-making discussed above apply to end-oflife decisions, although there are reasons for thinking that the cognitive rigidity, hopelessness, and negative outlook associated with depression incline patients in the direction of suicide. Finally, the presence of depression does not necessarily preclude the possibility that an individual seeking assisted suicide can make a rational and competent decision (Rosenfeld, 2000, p. 481).

In the context of assisted suicide, the analysis of this article suggests that when patients present signs of depression: (i) special efforts should be made to assess the decision-making competency of the patient and (ii) efforts should be made to treat the depression. Five heuristic strategies that should be followed by physicians when a patient requests physician-assisted suicide or euthanasia are (Rosenblatt \& Block, 2001, p. 320):

(1) The patient's reasons for their request should be clarified

(2) The patient's request should be reassessed after pain and other symptoms have been treated 
(3) The patient's request should be reassessed after psychological and social distress have been treated

(4) The physician-patient relationship should be assessed

(5) The patient's decision-making capacity should be assessed

The analysis of this article has implications primarily for (5) and (3). With respect to (5), cognitive rigidity is a specific deficit related to decision making that clinicians should take into consideration. With respect to (3), there are known pharmacological and cognitive interventions for depressed patients who are suicidal.

The primary conclusion drawn in this article pertains to (5): when a patient show signs of depression, his or her decision-making capacity should be properly evaluated by a mental health professional to ensure that the patient is presenting good reasons for requesting physicianassisted suicide. Judgments regarding whether a patient is cognitively rigid should be assessed (e.g., using tools such as the Iowa Gambling Task, the Wisconsin Card Sorting Test, or the Trail Making Test), since this trait may be impairing a patient's capacity to make a competent decision about ending his or her life. Moreover, different ways in which a patient's depression might negatively affect their decision-making process should be openly discussed with the patient (Rosenblatt \& Block, 2001). In the context of physician-assisted suicide, the crucial components of decision-making capacity include being capable of communicating a voluntary decision, having the capacity to reason and deliberate about the information, and holding a stable set of values (Rosenblatt \& Block, 2001, p. 324). Among these variables, there is evidence that the capacity to reason and deliberate about information is compromised by the potential cognitive rigidity presented by a patient.

A secondary conclusion of this article pertains to (3): when patients show signs of depression, efforts should be made to treat the depression before granting a request for assisted suicide. Questions concerning the efficacy of treatments for depression are controversial. Double-blind studies have indicated that antidepressant medications are effective for treating depressive disorders and that $50-70 \%$ of patients receiving antidepressants show some improvement (Depression Guideline Panel, 1993). Other studies indicate that psychotherapy (i.e., cognitive behavioral therapy, interpersonal psychotherapy) have comparable benefits to antidepressant treatment (Elkin et al., 1989). Generally, findings suggest that prescribing antidepressants or psychotherapy for depression will only have modest benefits for depressed patients; however, treatment will be most beneficial for patients who have more severe forms of depression (Elkin et al., 1989; Elkin et al., 1995; Kirsch et al., 2008; Sotsky et al., 1991). For the most severe forms of depression, there is limited evidence that antidepressants are superior to psychotherapy (Cuijpers et al., 2008; Imel et al., 2008). With respect to suicidal populations, some community studies have estimated that medications for mood disorders reduce the risk of suicide by three or four times (Angst et al., 2002), and some studies suggest that selective serotonin reuptake inhibitors are superior for producing a rapid alleviation of suicidal symptoms (Kapur, Mieczkowski, \& Mann, 1992). In cases where a patient exhibits problem-solving deficits or signs of cognitive rigidity, psychological interventions that target these deficits (e.g., problemsolving training, cognitive shift training, interventions that promote cognitive flexibility) may be warranted. This recommendation is especially salient given that there is some evidence that cognitive behavioral interventions that focus on problem-solving are highly effective at reducing suicide ideation (Joiner, Voelz, \& Rudd, 2001; van der Sande et al., 1997). 


\section{Conclusion}

In this article, I argued that depression and suicide are natural kinds insofar as they are classes constituted by distinct neurobiological mechanisms, e.g., deficient serotonin activity due to insensitive 5-HT receptors. The significance of this argument is that the natural (biological) basis of these classes allows for projectable inferences to be made about members of a kind. In the context of assisted suicide, inferences concerning the decision-making competence of depressed patients considering assisted suicide are extremely important. I reviewed evidence that some depressed patients who are suicidal present deficits in tasks of executive functioning (cognitive rigidity) and that this impairment in decision-making is associated with deficient serotonin projections to the orbitofrontal cortex. This suggests that special attention should be paid to the decision-making competence of depressed patients requesting physician-assisted suicide.

The analysis of this article has further implications for psychiatric classification, research on suicide ideation, and treatment interventions for suicidal individuals. At present, the diagnostic criteria for major depression do not include problem-solving deficits. As discussed in this article, general problem-solving deficits due to failures of executive functioning (expressed in patients as cognitive rigidity) is a strong predictor for suicide ideation among depressed patients. Hence, there are good theoretical reasons for including problem-solving deficits or mental inflexibility among the criteria required for a DSM diagnosis of depression (especially for more severe forms of depression). With respect to research on suicide ideation, more efforts should be directed towards understanding the complex interactions among cognitive rigidity, hopelessness, and negative outlook. Research on the biological bases of these cognitive traits could potentially clarify the causal basis of suicide ideation. Finally, given the considerable role that cognitive rigidity appears to play in suicide ideation, more efforts should be made to understand precisely how this particular cognitive trait contributes to suicide ideation and to develop specific interventions aimed at alleviating cognitive rigidity among depressed individuals.

\section{Acknowledgements}

I am grateful to Kate Padgett-Walsh, Paul Thagard, Stephen Biggs, Inmaculada de Melo-Martín, and an anonymous referee of this journal for very helpful comments and suggestions on earlier drafts of this article. I would also like to express my gratitude to Ian Hacking, Christopher DiTeresi, and Bill Wimsatt for earlier discussions that helped to shape my views on natural kinds in psychiatry.

\section{References}

American Psychiatric Association (2000). Diagnostic and statistical manual of mental disorders, 4th ed. (text rev.). Washington, DC: American Psychiatric Association. 
Angst, F., Stassen, H. H., Clayton, P. J., \& Angst, J. (2002). Mortality of patients with mood disorders: Follow-up over 34-48 years. Journal of Affective Disorders, 68 (2-3), 167-181.

Arias, E., Anderson, R. N., Kung, H. C., Murphy, S. L., \& Kochanek, K. D. (2003). Deaths: Final data for 2001. National Vital Statistics Reports, vol. 52, no. 3. Hyattsville, MD: National Center for Health Statistics.

Åsberg, M., Träskmann, L., \& Thorén, P. (1976). 5-HIAA in the cerebrospinal fluid: A biochemical suicide predictor? Archives of General Psychiatry, 33 (10), 1193-1197.

Austin, M. -P., Ross, M., Murray, C., O’Caŕroll, R. E., Ebmeier, K. P., \& Goodwin, G. M. (1992). Cognitive function in major depression. Journal of Affective Disorders, 25 (1), 21-29.

Back, A. L., Wallace, J. I., Starks, H. E., \& Pearlman, R. A. (1996). Physician-assisted suicide and euthanasia in Washington state: Patient requests and physician responses. Journal of the American Medical Association, 275 (12), 919-925.

Bechtel, W., \& Richardson, R. C. (1993). Discovering complexity: Decomposition and localization as strategies in scientific research. Princeton, NJ: Princeton University Press.

Beck, A. T., Kovacs, M., \& Weissman, A. (1975). Hopelessness and suicidal behavior: An overview. Journal of the American Medical Association, 234 (11), 1146-1149.

Beebee, H., \& Sabbarton-Leary, N. (2010). Are psychiatric kinds 'real'? European Journal of Analytic Philosophy, 6 (1), 11-27.

Benkelfat, C., Ellenbogen, M. A., Dean, P., Palmour, R. M., \& Young, S. N. (1994). Moodlowering effect of tryptophan depletion: Enhanced susceptibility in young men at genetic risk for major affective disorders. Archives of General Psychiatry, 51 (9), 687-700. 
Bird, A. \& Tobin, E. (2010). Natural kinds. In E. N. Zalta (Ed.), The Stanford encyclopedia of philosophy (Summer 2010 ed.). $<$ http://plato.stanford.edu/archives/sum2010/entries/natural-kinds/>.

Boorse, C. (1975). On the distinction between disease and illness. Philosophy and Public Affairs, $5(1), 49-68$.

Boorse, C. (1976). What a theory of mental health should be. Journal for the Theory of Social Behaviour, $6(1), 61-84$.

Boorse, C. (1977). Health as a theoretical concept. Philosophy of Science, 44 (4), 542-573.

Boorse, C. (1997). A rebuttal on health. In J. M. Humber \& R. F. Almeder (Eds.), What is disease? (pp. 3-143). Totowa, NJ: Humana Press.

Boyd, R. (1985). Observations, explanatory power, and simplicity: Toward a nonHumean account. In P. Achinstein \& O. Hannaway (Eds.), Observation, experiment, and hypothesis in modern physical science (pp. 47-94). Cambridge, MA: MIT Press.

Boyd, R. (1988). How to be a moral realist. In G. Sayre-McCord (Ed.), Moral realism (pp. 181228). Ithaca, NY: Cornell University Press.

Boyd, R. (1989). What realism implies and what it does not. Dialectica, 43 (1-2), 5-29.

Boyd, R. (1990). Realism, approximate truth, and philosophical method. In C. W. Savage (Ed.), Scientific theories. Minnesota studies in the philosophy of science, vol. 14 (pp. 355-391). Minneapolis, MN: University of Minnesota Press.

Boyd, R. (1991). Realism, anti-foundationalism and the enthusiasm for natural kinds. Philosophical Studies, 61 (1-2), 127-148.

Boyd, R. (1999). Homeostasis, species, and higher taxa. In R. A. Wilson (Ed.), Species: New interdisciplinary essays (pp. 141-185). Cambridge, MA: MIT Press.

Boyd, R. (2010). Realism, natural kinds, and philosophical methods. In H. Beebee \& N. 
Sabbarton-Leary (Eds.), The semantics and metaphysics of natural kinds (pp. 212-234). New York: Routledge.

Breitbart, W., Rosenfeld, B. D., \& Passik, S. D. (1996). Interest in physician-assisted suicide among ambulatory HIV-infected patients. American Journal of Psychiatry, 153 (2), 238242.

Breitbart, W., Rosenfeld, B., Pessin, H., Kaim, M., Funesti-Esch, J., Nelson, C. J., \& Brescia, R. (2000). Depression, hopelessness, and desire for hastened death in terminally ill patients with cancer. Journal of the American Medical Association, 284 (22), 2907-2911.

Brent, D. A., Bridge, J., Johnson, B. A., \& Conolly, J. (1996). Suicidal behavior runs in families: A controlled family study of adolescent suicide victims. Archives of General Psychiatry, $53(12), 1145-1152$.

Brown, G. K., Beck, A. T., Steer, R. A., \& Grisham, J. R. (2000). Risk factors for suicide in psychiatric outpatients: A 20-year prospective study. Journal of Consulting and Clinical Psychology, 68 (3), 371-377.

Bunney, W. E., Fawcett, J. A., Davis, J. M., \& Gifford, S. (1969). Further evaluation of urinary 1-hydroxycorticosteroids in suicidal patients. Archives of General Psychiatry, 21 (2), 138-150.

Carlson, N. R. (2008). Foundations of physiological psychology, 7th ed. Boston: Allyn and Bacon.

Chen, Y. W., \& Dilsaver, S. C. (1996). Lifetime rates of suicide attempts among subjects with bipolar and unipolar disorders relative to subjects with other axis I disorders. Biological Psychiatry, 39 (10), 896-899.

Chochinov, H. M., Wilson, K. G., Enns, M., Mowchun, N., Lander, S., Levitt, M., \& Clinch, J. J. (1995). Desire for death in the terminally ill. American Journal of Psychiatry, 152 (8), 1185-1191.

Cholbi, M. (2011). Suicide: The philosophical dimensions. Peterborough, ON: Broadview. Cholbi, M. (2012). Suicide. In E. N. Zalta (Ed.), The Stanford encyclopedia of philosophy 
(Winter 2010 ed.). <http://plato.stanford.edu/archives/win2012/entries/suicide/>.

Cooper, R. (2005). Classifying madness: A philosophical examination of the Diagnostic and Statistical Manual of Mental Disorders. Dordrecht: Springer.

Cooper, R. (2007). Psychiatry and philosophy of science. Montreal \& Kingston: McGill-Queen's University Press.

Craver, C. F., \& Darden, L. (2001). Discovering mechanisms in neurobiology: The case of spatial memory. In P. K. Machamer, R. Grush, \& P. McGlaughlin (Eds.), Theory and method in the neurosciences (pp. 112-137). Pittsburgh, PA: University of Pittsburgh Press.

Cuijpers, P., van Straten, A., van Oppen, P., \& Andersson, G. (2008). Are psychological and pharmacologic interventions equally effective in the treatment of adult depressive disorders? A meta-analysis of comparative studies. Journal of Clinical Psychiatry, 69 (11), 1675-1685.

Damasio, H., Grabowski, T., Frank, R., Galaburda, A. M., \& Damasio, A. R. (1994). The return of Phineas Gage: Clues about the brain from the skull of a famous patient. Science, 264 (5162), 1102-1105.

Daniels, N. (1981). Health-care needs and distributive justice. Philosophy and Public Affairs, 10 (2), 146-179.

Daniels, N. (1985). Just health care. Cambridge: University of Cambridge Press.

Daniels, N. (2008). Just health: Meeting health needs fairly. Cambridge: University of Cambridge Press.

Davidson, R. J., Pizzagalli, D., Nitscheke, J. B., \& Putnam, K. (2002). Depression: Perspectives from affective neuroscience. Annual Review of Psychology, 53, 545-574.

Degl'Innocenti, A., Ågren, H., \& Backman, A. (1998). Executive deficits in major depression. Acta Psychiatrica Scandinavica, 97 (3), 182-188.

Delgado, P. L. (2000). Depression: The case for a monoamine deficiency. Journal of Clinical 
Psychiatry, 61 (supp. 6), 7-11.

Delgado, P. L., Charney, D. S., Price, L. H., Aghajanian, G. K., Landis, H., \& Heninger, G. R. (1990). Serotonin function and the mechanism of antidepressant action: Reversal of antidepressant induced remission by rapid depletion of plasma tryptophan. Archives of General Psychiatry, 47 (5), 411-418.

Depression Guideline Panel (1993). Depression in primary care: Volume 2. Treatment of major depression. Rockville, MD: US Department of Health and Human Services, Agency for Health Care Policy and Research.

Dieserud, G. Røysamb, E., Braverman, M. T., Dalgard, O. S., \& Ekeberg, Ø. (2003). Predicating repetition of suicide attempt: A prospective study of 50 suicide attempters. Archives of Suicide Research, 7 (1), 1-15.

Dupré, J. (1981). Natural kinds and biological taxa. Philosophical Review, 90 (1), 66-90.

Dupré, J. (1993). The disorder of things: Metaphysical foundations of the disunity of science. Cambridge, MA: Harvard University Press.

Dupré, J. (2001). In defense of classification. Studies in History and Philosophy of Biological and Biomedical Sciences, 32 (2), 203-219.

Dupré, J. (2002). Is 'natural kind' a natural kind? The Monist, 85 (1), 24-49.

Egeland, J. A., \& Sussex, J. N. (1985). Suicide and family loading for affective disorders. Journal of the American Medical Association, 254 (7), 915-918.

Elkin, I., Gibbons, R. D., Shea, M.T., Sotsky, S.M., Watkins, J.T., Pilkonis, P.A., \& Hedeker, D. (1995). Initial severity and differential treatment outcome in the National Institute of Mental Health Treatment of Depression Collaborative Research Program. Journal of Consulting and Clinical Psychology, 63 (5): 841-847.

Elkin, I., Shea, M. T., Watkins, J. T., Imber, S. D., Sotsky, S. M., Collins, J. F., Glass, D. R., Pilkonis, P. A., Leber, W. R., Docherty, J. P., Fiester, S. J., \& Parloff, M. B. (1989). NIMH Treatment of Depression Collaborative Research Program: 1. General effectiveness of treatments. Archives of General Psychiatry, 46 (11), 971-983. 
Eslinger, P. J., \& Damasio, A. R. (1985). Severe disturbance of higher cognition after bilateral frontal lobe ablation: Patient EVR. Neurology, 35 (12), 1731-1741.

Fangmann, P., Assion, H.-J., Juckel, G., González, C. Á., \& López-Muñoz, F. (2008). Half a century of antidepressant drugs: On the clinical introduction of monoamine oxidase inhibitors, tricyclics, and tetracyclics. Part II: Tricyclics and tetracyclics. Journal of Clinical Psychopharmacology, 28 (1), 1-4.

Fossati, P., Ergis, A. M., \& Allilaire, J. F. (2002). Executive functioning in unipolar depression: A review. L'Encephale, 28 (2), 97-107.

Freedman, D. X. (1984). Psychiatric epidemiology counts. Archives of General Psychiatry, 41 (10), 931-933.

Ganzini L., Goy, E. R., \& Dobscha, S. K. (2008). Prevalence of depression and anxiety in patients requesting physicians' aid in dying: Cross sectional survey. $B M J, 337$, a1682. $<$ http://dx.doi.org/10.1136/bmj.a1682>

Gardner, R. J. M. \& Sutherland, G. R. (2004). Chromosome abnormalities and genetic counseling, 3rd ed. New York: Oxford University Press.

Glennan, S. (1996). Mechanisms and the nature of causation. Erkenntnis, 44 (1), 49-71.

Glennan, S. (2002). Rethinking mechanistic explanation. Philosophy of Science, 69 (S3), S342-S353.

Goodman, N. (1983). Fact, fiction, and forecast, 4th ed. Cambridge, MA: Harvard University Press.

Goodwin, G. M. (1997). Neuropsychological and neuroimaging evidence for the involvement of the frontal lobes in depression. Journal of Psychopharmacology, 11 (2), 115-122.

Hacking, I. (1986). Making up people. In T. Heller, M. Sosna, \& D. Wellberry (Eds), Reconstructing individualism: Autonomy, individuality, and the self in Western thought (pp. 222-236). Stanford, CA: Stanford University Press. 
Hacking, I. (1990). The taming of chance. Cambridge: University of Cambridge Press.

Hacking, I. (1995). The looping effects of human kinds. In D. Sperber, D. Premack, \& A. J. Premack (Eds.), Causal cognition: A multidisciplinary debate (pp. 351-383). Oxford: Clarendon Press.

Hacking, I. (1999). The social construction of what? Cambridge, MA: Harvard University Press. Hacking, I. (2007a). Kinds of people: Moving targets. Proceedings of the British Academy, 151, 285-318.

Hacking, I. (2007b). Natural kinds: Rosy dawn, scholastic twilight. In A. O’Hear (Ed.), Philosophy of science (pp. 203-239). Cambridge: Cambridge University Press.

Haslam, N. (2002). Kinds of kinds: A conceptual taxonomy of psychiatric categories. Philosophy, Psychiatry, \& Psychology, 9 (3), 203-217.

Healy, D. (1997). The anti-depressant era. Cambridge, MA: Harvard University Press.

Henriksson, M. M., Aro, H. M., Marttunen, M. J., Heikkinenen, M. E., Isometsä, E. T., Kuoppasalmi, K. I., \& Lönnqvist, J. K. (1993). Mental disorders and comorbidity in suicide. American Journal of Psychiatry, 150 (6), 935-940.

Hirschfeld, R. M. A. (2000). History and evolution of the monoamine hypothesis of depression. Journal of Clinical Psychiatry, 61 (supp. 6), 4-6.

Imel, Z. E., Malterer, M. B., McKay, K. M., \& Wampold, B. E. (2008). A meta-analysis of psychotherapy and medication in unipolar depression and dysthymia. Journal of Affective Disorders, 110 (3), 197-206.

Ingram, R. E., Scott, W. D., \& Hamill, S. (2009). Depression: Social and cognitive aspects. In P. H. Blaney \& T. Millon (Eds.), Oxford textbook of psychopathology, 2nd ed. (pp. 230252). New York: Oxford University Press.

Johnson, S. L., Joormann, J., LeMoult, J., \& Miller, C. (2009). Mood disorders: Biological bases. In P. H. Blaney \& T. Millon (Eds.), Oxford textbook of psychopathology, 2nd ed. (pp. 198-229). New York: Oxford University Press.

Joiner, T. E., Voeltz, Z. R., \& Rudd, M. D. (2001). For suicidal young adults with comorbid 
depressive and anxiety disorders, problem-solving treatment may be better than treatment as usual. Professional Psychology: Research and Practice, 32 (3), 278-282.

Jollant, F., Bellivier, F., Leboyer, M., Astruc, B., Torres, S., Verdier, R., Castelnau, D., Malafosse, A., \& Courtet, P. (2005). Impaired decision making in suicide attempters. American Journal of Psychiatry, 162 (2), 304-310.

Kapur, S., Mieczkowski, T., \& Mann, J. J. (1992). Antidepressant medications and the relative risk of suicide attempt and suicide. Journal of the American Medical Association, 268 (24), 3441-3445.

Keilp, J. G., Sackeim, H. A., Brodsky, B. S., Oquendo, M. A., Malone, K. M., \& Mann, J. J. (2001). Neuropsychological dysfunction in depressed suicide attempters. American Journal of Psychiatry, 158 (5), 735-741.

Kelly, B., Burnett, P., Pelusi, D., Badger, S., Varghese, \& Robertson, M. (2003). Factors associated with the wish to hasten death: A study of patients with terminal illness. Psychological Medicine, 33 (1), 75-81

Kendell, R. E. (1975). The concept of disease and its implications for psychiatry. British Journal of Psychiatry, 127 (4), 305-315.

Kendler, K. S., \& Prescott, C. A. (1999). A population-based twin study of lifetime major depression in men and women. Archives of General Psychiatry, 56 (1), 529-535.

Kendler, K. S., Zachar, P., \& Craver, C. (2011). What kinds of things are psychiatric disorders? Psychological Medicine, 41 (6), 1143-1150.

Kessler, R. C., Berglund, P., Demler, O., Jin, R., Koretz, D., Merikangas, K. R., Rush, A. J., Walters, E. E., \& Wang, P. S. (2003). The epidemiology of major depressive disorder: Results from the National Comorbidity Survey Replication (NCS-R). Journal of the American Medical Association, 289 (23), 3095-3105.

Kessler, R. C., McGonagle, K. A., Zhao, S., Nelson, C. B., Hughes, M., Eshleman, S., Wittchen, H. U., \& Kendler, K. S. (1994). Lifetime and 12-month prevalence of DSM-III-R 
psychiatric disorders in the United States: Results from the National Comorbidity Survey. Archives of General Psychiatry, 51 (1), 8-19.

Kirsch, I., Deacon, B. J., Huedo-Medina, T. B., Scoboria, A., Moore, T. J., \& Johnson, B. T. (2008). Initial severity and antidepressant benefits: A meta-analysis of data submitted to the Food and Drug Administration. PLoS Med, 5 (2): e45. $<$ http://dx.doi.org/10.1371/journal.pmed.0050045>

Kleinman, A. (1977). Depression, somatization, and the new cross-cultural psychiatry. Social Science and Medicine, 11 (1), 3-10.

Kleinman, A. (1988). Rethinking psychiatry: From cultural category to personal experience. New York: The Free Press.

Kleinman, A., \& Good, B. (Eds.) (1985). Culture and depression: Studies in the anthropology and cross-cultural psychiatry of affect and disorder. Berkeley, CA: University of California Press.

Kring, A. M., Davison, G., Neal, J. M., \& Johnson, S. L. (2007). Abnormal psychology, 10th ed. Hoboken, NJ: John Wiley \& Sons.

LaPorte, J. (2004). Natural kinds and conceptual change. Cambridge: Cambridge University Press.

Lavery, J. V., Boyle, J. Dickens, B. M., Maclean, H., \& Singer, P. A. (2001). Origins of the desire for euthanasia and assisted suicide in people with HIV-1 or AIDS: A qualitative study. The Lancet, 358 (9272), 362-367.

Levene, I., \& Parker, M. (2011). Prevalence of depression in granted and refused requests for euthanasia and assisted suicide: A systematic review. Journal of Medical Ethics, 37 (4), 205-211.

Liotti, M., Mayberg, H. S., McGinnis, S., Brannan, S. L., \& Jerabek, P. (2002). Unmasking disease-specific cerebral blood flow abnormalities: Mood challenge in patients with 
remitted unipolar depression. American Journal of Psychiatry, 159 (11), 1830-1840.

Linehan, M. M. (1997). Behavioral treatments of suicidal behaviors: Definitional obfuscation and treatment outcomes. In D. M. Stoff \& J. J. Mann (Eds.), Neurobiology of suicide (pp. 302-327). New York: Annals of the New York Academy of Sciences.

Linehan, M. M., \& Shearin, E. N. (1988). Lethal stress: A social-behavioral model of suicidal behavior. In S. Fisher \& J. Reason (Eds.), Handbook of life stress, cognition, and health (pp. 265-285). Chichester: Wiley.

López-Muñoz, F., \& Álamo, C. (2009). Monoaminergic neurotransmission: The history of the discovery of antidepressants from 1950s to today. Current Pharmaceutical Design, 15 (14), 1563-1586.

López-Muñoz, F., Álamo, C., Jeckel, G., \& Assion, H.-J. (2007). Half a century of antidepressant drugs: On the clinical introduction of monoamine oxidase inhibitors, tricyclics, and tetracyclics. Part I: Monoamine oxidase inhibitors. Journal of Clinical Psychopharmacology, 27 (6), 555-559.

Luscomb, R. L., Clum, G. A., \& Patsiokas, A. T. (1980). Mediating factors in the relationship between life stress and suicide attempting. Journal of Nervous and Mental Disease, 168 (11), 644-650.

Machamer, P. (2004). Activities and causation: The metaphysics and epistemology of mechanisms. International Studies in the Philosophy of Science, 18 (1), 27-39.

Machamer, P., Darden, L., \& Craver, C. F. (2000). Thinking about mechanisms. Philosophy of Science, 67 (1), 1-25.

Maes, M., \& Meltzer, H. Y. (1995). The serotonin hypothesis of major depression. In F. E. Bloom \& D. J. Kupfer (Eds.), Psychopharmacology: The fourth generation of progress 
(pp. 933-944). New York: Raven Press.

Mann, J. J. (1998). The neurobiology of suicide. Nature Medicine, 4 (1), 25-30.

Mann, J. J., Brent, D. A., \& Arango, V. (2001). The neurobiology and genetics of suicide and attempted suicide: A focus on the serotonergic system. Neuropsychopharmacology, 24 (5), 467-477.

Mann, J. J., Waternaux, C., Haas, G. L., \& Malone, K. M. (1999). Toward a clinical model of suicidal behavior in psychiatric patients. American Journal of Psychiatry, 156 (2), 181 189.

Martin, D. J., Oren, Z., \& Boone, K. (1991). Major depressives' and dysthymics’ performance on the Wisconsin Card Sorting Test. Journal of Clinical Psychology, 47 (5), 684-690.

Marzuk, P. M., Hartwell, N., Leon, A. C., \& Portera, L. (2005). Executive functioning in depressed patients with suicidal ideation. Acta Psychiatrica Scandinavica, 112 (4), 294301.

McLeavey, B. C., Daly, R. J., Murray, C. M., O’Riodan, J., \& Taylor, M. (1987). Interpersonal problem-solving deficits in self-poisoning patients. Suicide and Life-Threatening Behavior, 17 (1), 33-49.

McKim, W. A. (2007). Drugs and behavior: An introduction to behavioral pharmacology, 6th ed. Upper Saddle River, NJ: Prentice Hall.

Meltzer, H. Y., \& Lowy, M. T. (1987). The serotonin hypothesis of depression. In H. Y. Meltzer (Ed.), Psychopharmacology: The third generation of progress (pp. 513-526). New York: Raven Press.

Moore, P., Landolt, H. P., Seifritz, E., Clark, C., Bhatti, T., Kelsoe, J., Rapaport, M., \& Gillin, J. C. (2000). Clinical and physiological consequences of rapid tryptophan depletion. Neuropsychopharmacology, 23 (6), 601-622. 
Murphy, D. (2006). Psychiatry in the scientific image. Cambridge, MA: MIT Press.

Nemeroff, C. B., Owens, M. J., Bisette, G., Andorn, A. C., \& Stanley, M. (1988). Reduced corticotropin releasing factor binding sites in the frontal cortex of suicide victims. Archives of General Psychiatry, 45 (6), 577-579.

Nestler, E. J., Barrot, M., DiLeone, R. J., Eisch, A. J., Gold, S. J., \& Monteggia, L. M. (2002). Neurobiology of depression. Neuron, 34 (1), 13-25.

Neuringer, C. (1961). Dichotomous evaluations in suicidal individuals. Journal of Consulting Psychology, 25 (5), 445-449.

Neuringer, C. (1964). Rigid thinking in suicidal individuals. Journal of Consulting Psychology, $28(1), 54-58$.

Ogilvie, A. D., Battersby, S., Fink, G., Harmar, A. J., Goodwin, G. M., Bubb, V. J., \& Dale Smith, C. A. (1996). Polymorphism in serotonin transporter gene associated with susceptibility to major depression. The Lancet, 347 (9003), 731-733.

Owens, M. J. (2004). Selectivity of antidepressants: From the monoamine hypothesis of depression to the SSRI revolution and beyond. Journal of Clinical Psychiatry, 65 (supp. 4), 5-10.

Patsiokas, A. T., Clum, G. A., \& Luscomb, R. L. (1979). Cognitive characteristics of suicide attempters. Journal of Consulting and Clinical Psychology, 47 (3), 478-484.

Perrah, M., \& Wichman, H. (1987). Cognitive rigidity in suicide attempters. Suicide and LifeThreatening Behavior, 17 (3), 251-255.

Pollock, L. R., \& Williams, J. M. G. (1998). Problem solving and suicidal behavior. Suicide and Life-Threatening Behavior, 28 (4), 375-387.

Powell, K., \& Miklowitz, D. (1994). Frontal lobe dysfunction in the affective disorders. Clinical Psychology Review, 14 (6), 525-546.

Quine, W. V. (1969). Natural kinds. In W. V. Quine, Ontological relativity and other essays, (pp. 114-138). New York: Columbia University Press.

Rickelman, B. L., \& Houfek, J. F. (1995). Toward an interactive model of suicidal behaviors: 
Cognitive rigidity, attributional style, stress, and depression. Archives of Psychiatric Nursing, 9 (3), 158-168.

Risch, N., Herrell, R., Lehner, T., Liang, K.-Y., Eaves, L., Hoh, J., Griem, A., Kovacs, M., Ott, J., \& Merikangas, K. R. (2009). Interaction between the serotonin transporter gene (5HTTLPR), stressful life events, and risk of depression: A meta-analysis. Journal of the American Medical Association, 301 (23), 2462-2471.

Rosenblatt, L., \& Block, S. D. (2001). Depression, decision making, and the cessation of lifesustaining treatment. Western Journal of Medicine, 175 (5), 320-325.

Rosenfeld, B. (2000). Assisted suicide, depression, and the right to die. Psychology, Public Policy, and Law, 6 (2): 467-488.

Roy, A. (1986). Genetics of suicide. Annals of the New York Academy of Sciences, 487 (1), 97105.

Roy, A. (1993). Genetic and biologic risk factors for suicide in depressive disorders. Psychiatric Quarterly, 64 (4), 609-612.

Roy, A., De Jong, J., \& Linnoila, M. (1989). Cerebrospinal fluid monoamine metabolites and suicidal behavior in depressed patients: A 5-year follow-up study. Archives of General Psychiatry, 46 (7), 609-612.

Roy, A., Segal, N. L., Centerwall, B. S., \& Robinette, C. D. (1991). Suicide in twins. Archives of General Psychiatry, 48 (1), 29-32.

Roy, A., Segal, N. L., \& Sarchiapone, M. (1995). Attempted suicide among living co-twins of twin suicide victims. American Journal of Psychiatry, 152 (7), 1075-1076.

Sachar, E. J., \& Baron, M. (1979). The biology of affective disorders. Annual Review of Neuroscience, 2, 515-518.

Sartorius, N., Davidian, H., Ernberg, G., Fenton, F. R., Fujii, I., Gastpar, M., Gulbinat, W., Jablensky, A., Kielhotz, P., Lehmann, H. E., Naraghi, M., Shimizu, M., Shinfuku, N., \& Takahashi, R. (1983). Depressive disorders in different cultures: Report on the WHO collaborative study on standardized assessment of depressive disorders. Geneva: 


\section{World Health Organization.}

Schotte, D. E., \& Clum, G. A. (1987). Problem-solving skills in suicidal psychiatric patients. Journal of Consulting and Clinical Psychology, 55 (1), 49-54.

Schulsinger, F., Kety, S. S., Rosenthal, D., \& Wender, P. H. (1979). A family study of suicide. In M. Schou \& E. Strömgren (Eds.), Origin, prevention, and treatment of affective disorders (pp. 277-288). New York: Academic Press.

Sedgwick, P. (1982). Psycho politics: Laing, Foucault, Goffman, Szasz and the future of mass psychiatry. New York: Harper \& Row.

Slater, M. H. (2005). Monism on the one hand, pluralism on the other. Philosophy of Science, 72 (1), 22-42.

Sotsky, S. M., Glass, D. R., Shea, M. T., Pilkonis, P. A., Collins, J. F., Elkin, I., Watkins, J. T., Imber, S. D., Leber, W. R., \& Moyer, J. (1991). Patient predictors of response to psychotherapy and pharmacotherapy: Findings in the NIMH Treatment of Depression Collaborative Research Program. American Journal of Psychiatry, 148 (8), 997-1008.

Statham, D. J., Heath, A. C., Madden, P. A. F., Bucholz, K. K., Bierut, L., Dinwiddie, S. H., Slutske, W. S., Dunne, M. P., \& Martin, N. G. (1998). Suicidal behavior: An epidemiological and genetic study. Psychological Medicine, 28 (4), 839-855.

Sullivan, P. F., Neale, M. C., \& Kendler, K. S. (2000). Genetic epidemiology of major

depression: Review and meta-analysis. American Journal of Psychiatry, 157 (10), 1552-1562.

Szasz, T. S. (1960). The myth of mental illness. American Psychologist, 15 (2), 113-118.

Szasz, T. S. (1974). The myth of mental illness: Foundations of a theory of personal conduct, 2nd ed. New York: Harper \& Row.

Szasz, T. S. (1998 March). Summary statement and manifesto. Unpublished document. $<\mathrm{http}: / /$ www.szasz.com/manifesto.html $>$

Tabery, J. G. (2004). Synthesizing activities and interactions in the concept of a mechanism. Philosophy of Science, 71 (1), 1-15.

Träskmann, L., Åsberg, M., Bertilsson, L., \& Sjöstrand, L. (1981). Monoamine metabolites in 
CSF and suicidal behavior. Archives of General Psychiatry, 38 (6), 631-636.

Tsou, J. Y. (2007). Hacking on the looping effects of psychiatric classifications: What is an interactive and indifferent kind? International Studies in the Philosophy of Science, 21 (3), 329-344.

Tsou, J. Y. (2012). Intervention, causal reasoning, and the neurobiology of mental disorders: Pharmacological drugs as experimental instruments. Studies in History and Philosophy of Biological and Biomedical Sciences, 43 (2), 542-551.

van der Lee, M. L., van der Bom, J. G., Swarte, N. B., Heintz, A. P. M., de Graeff, A., \& van den Bout, J. (2005). Euthanasia and depression: A prospective cohort study among terminally ill cancer patients. Journal of Clinical Oncology, 23 (27), 6607-6612.

van der Sande, R., Buskens, E., Allart, E., van der Graaf, Y., \& van Engeland, H. (1997).

Psychosocial intervention following suicide attempt: A systematic review of treatment interventions. Acta Psychiatrica Scandinavica, 96 (1), 43-50.

Veiel, H. O. F. (1997). A preliminary profile of neuropsychological deficits associated with major depression. Journal of Clinical and Experimental Neuropsychology, 19 (4), 587603.

Weishaar, M. E. (1996). Cognitive risk factors in suicide. In P. M. Salkoviskis (Ed.), Frontiers of cognitive therapy (pp. 226-249). New York: The Guilford Press.

Weishaar, M. E., \& Beck, A. T. (1992). Hopelessness and suicide. International Review of Psychiatry, 4 (2), 177-184.

Weissman, M. M., Bland, R. C., Canino, G. C., Faravelli, C., Greenwald, S., Hwu, H.-G., Joyce, P. R., Karam, E. G., Lee, C.-K., Lellouch, J., Lépine, J.-P., Newman, S. C., Rubio-Stipec, M., Wells, J. E., Wickramaratne, P. J., Wittchen, H.-U., \& Yeh, E. K. (1996). Crossnational epidemiology of major depression and bipolar disorder. Journal of the American Medical Association, 276 (4), 293-299.

Zachar, P. (2000). Psychiatric disorders are not natural kinds. Philosophy, Psychiatry, \& Psychology, 7 (3), 167-182. 